\title{
Reduced insulin clearance and lower insulin-degrading enzyme expression in the liver might contribute to the thrifty phenotype of protein-restricted mice
}

\author{
Luiz F. Rezende*, Rafael L. Camargo, Renato C. S. Branco, Ana P. G. Cappelli, Antonio C. Boschero \\ and Everardo M. Carneiro \\ Department of Structural and Functional Biology, Institute of Biology, State University of Campinas (UNICAMP), \\ PO Box 6109, Campinas, SP, CEP 13083-865, Brazil
}

(Submitted 17 June 2013 - Final revision received 21 January 2014 - Accepted 24 January 2014 - First published online 18 July 2014)

\begin{abstract}
Nutrient restriction during the early stages of life usually leads to alterations in glucose homeostasis, mainly insulin secretion and sensitivity, increasing the risk of metabolic disorders in adulthood. Despite growing evidence regarding the importance of insulin clearance during glucose homeostasis in health and disease, no information exists about this process in malnourished animals. Thus, in the present study, we aimed to determine the effect of a nutrient-restricted diet on insulin clearance using a model in which 30-d-old C57BL/6 mice were exposed to a protein-restricted diet for 14 weeks. After this period, we evaluated many metabolic variables and extracted pancreatic islet, liver, gastrocnemius muscle (GCK) and white adipose tissue samples from the control (normal-protein diet) and restricted (low-protein diet, LP) mice. Insulin concentrations were determined using RIA and protein expression and phosphorylation by Western blot analysis. The LP mice exhibited lower body weight, glycaemia, and insulinaemia, increased glucose tolerance and altered insulin dynamics after the glucose challenge. The improved glucose tolerance could partially be explained by an increase in insulin sensitivity through the phosphorylation of the insulin receptor/protein kinase B and AMP-activated protein kinase/acetyl-CoA carboxylase in the liver, whereas the changes in insulin dynamics could be attributed to reduced insulin secretion coupled with reduced insulin clearance and lower insulin-degrading enzyme (IDE) expression in the liver and GCK. In summary, protein-restricted mice not only produce and secrete less insulin, but also remove and degrade less insulin. This phenomenon has the double benefit of sparing insulin while prolonging and potentiating its effects, probably due to the lower expression of IDE in the liver, possibly with long-term consequences.
\end{abstract}

Key words: Thrifty phenotype: Insulin clearance: Insulin-degrading enzyme: Insulin secretion: Insulin sensitivity

There is a consensus that the detrimental alteration of glucose homeostasis, leading to the metabolic syndrome and type 2 diabetes, occurs due to a combination of genetic and environmental factors. Nutrition is a strong environmental factor, given that both an excess and a $\operatorname{lack}^{(1)}$ of nutrients are predisposing factors for the development of type 2 diabetes.

The development of the endocrine pancreas occurs during intra-uterine growth and also in the early postnatal stages ${ }^{(2)}$. Studies have shown decreased vascularisation and increased apoptosis to occur in the pancreatic islets of fetuses exposed to gestational protein restriction ${ }^{(3)}$. Therefore, protein restriction can permanently impair the development and function of the pancreatic islets.

Hales \& Barker $^{(4)}$ proposed the so-called thrifty phenotype to describe a situation in which an early-life exposure to a nutrient-restricted environment would lead to permanent, or at least long-lasting, changes in glucose homeostasis to cope with the challenge of maintaining an adequate supply of nutrients to peripheral tissues, without compromising blood glycaemia and body composition ${ }^{(5)}$. These changes would preserve nutrients and energy, maximising these resources in an 'economical' layout.

Dietary protein restriction after lactation is useful for understanding metabolic adaptations that might occur in adult life ${ }^{(6-8)}$. Although our animal model was not exposed to gestational or lactational malnutrition, protein malnourishment after weaning was able to induce physiological adaptations that could have an impact on glucose homeostasis in adult life.

Over the years, accumulated evidence has provided a solid background for the thrifty phenotype hypothesis and also that this phenotype includes changes in insulin secretion and sensitivity ${ }^{(9-12)}$. The downside is that once exposed to a regular diet, these individuals or animals still consume more and expend fewer nutrients and less energy, thereby

Abbreviations: AKT, protein kinase B; AMPK, AMP-activated protein kinase; GTT, glucose tolerance test; IDE, insulin-degrading enzyme; ITT, insulin tolerance test; KHBS, Krebs-Henseleit buffer solution; Ln, natural logarithm; LP, low-protein diet; NP, normal-protein diet; WAT, white adipose tissue. 
Table 1. Composition of the diets used in the study

\begin{tabular}{lcc}
\hline Ingredients (g/kg) & NP & LP \\
\hline Casein & 140 & $71 \cdot 5$ \\
Maize starch & $465 \cdot 7$ & $502 \cdot 5$ \\
Dextrinised maize starch & 155 & $166 \cdot 5$ \\
Sucrose & 100 & 121 \\
L-Cystine & $1 \cdot 8$ & 1 \\
Fibre & 50 & 50 \\
Soyabean oil & 40 & 40 \\
Mineral mix (AIN-93M) & 35 & 35 \\
Vitamin mix (AIN-93M) & 10 & 10 \\
Choline chlorhydrate & $2 \cdot 5$ & $2 \cdot 5$ \\
Energy (kcal/g) & $3 \cdot 88$ & $3 \cdot 88$ \\
Energy (kJ/g) & $16 \cdot 23$ & $16 \cdot 23$ \\
\hline
\end{tabular}

NP, normal-protein diet; LP, low-protein diet.

increasing the predisposition to develop obesity and type 2 diabetes $^{(5,13-16)}$

In a review of the initial hypothesis, Hales \& Barker ${ }^{(17)}$ wisely conceived of other possible changes in liver physiology that could help explain the thrifty phenotype. It is now well known that the plasma insulin concentration, or insulinaemia, is not solely dependent on the amount of insulin secreted by the pancreatic islets but also dependent, at least to the same extent, on the rate by which insulin is removed from the plasma, known as insulin clearance ${ }^{(18-23)}$.

Approximately $50 \%$ of the secreted insulin is removed from the plasma after its second passage through the liver, the organ that is involved in $70-80 \%$ of insulin clearance ${ }^{(24-26)}$. Insulin clearance itself is mainly controlled by insulin-degrading enzyme (IDE) expression and activity in the peripheral tissues and especially, as expected, in the liver ${ }^{(24,27)}$.

In the present study, we aimed to determine whether a lowprotein diet after weaning could contribute to the thrifty phenotype, including changes in insulin clearance and IDE expression mainly in the liver and also in the skeletal muscle and white adipose tissue (WAT).

\section{Materials and methods}

\section{Animals and experimental design}

In the present study, 30-d-old weaned $\mathrm{C} 57 \mathrm{BL} / 6$ mice were randomly distributed into two experimental groups in a $22^{\circ} \mathrm{C}$, humidity-controlled, $12 \mathrm{~h}$ light- $12 \mathrm{~h}$ dark cycle environment with free access to food and water in individual cages. A normal-protein diet (NP) was fed to one group and a low-protein diet (LP) to the other group for 14 weeks, after which the animals were subjected to experimental procedures. All the experiments were approved by the Ethics Committee of the State University of Campinas, and every effort was made to minimise animal suffering. The composition of the diets is given in Table 1, and it was the same as that described previously ${ }^{(6)}$.

\section{Western blot analysis}

Protein expression and phosphorylation were evaluated using Western blot analysis as described previously ${ }^{(28)}$.

\section{Collection of tissue samples}

Liver, gastrocnemius muscle and WAT samples were isolated from $14 \mathrm{~h}$ fasting mice and were then snap-frozen in liquid $\mathrm{N}_{2}$ and stored for subsequent protein extractions. Pancreatic islet samples were isolated from the mice by the collagenase method, as described previously ${ }^{(29)}$.

\section{Evaluation of pancreatic islet glucose-stimulated insulin secretion}

Batches of ten islets were pre-incubated for $1 \mathrm{~h}$ in KrebsHenseleit buffer solution (KHBS) containing $0.5 \mathrm{~g} / 1$ bovine serum albumin and $5.6 \mathrm{~mm}$-glucose and equilibrated at $95 \% \mathrm{O}_{2}$ and $5 \% \mathrm{CO}_{2}$ at $37^{\circ} \mathrm{C}$. The medium was discarded, and the islets were incubated for an additional $1 \mathrm{~h}$ in $1 \mathrm{ml}$ of KHBS containing 2.8 or 16.7 mm-glucose. Subsequently, the supernatant fraction was collected to evaluate insulin secretion, and the remaining islets were homogenised in an alcohol/acid solution to measure the total insulin content. Both insulin secretion and total content were evaluated using RIA, as described previously ${ }^{(30)}$.

\section{Intraperitoneal glucose tolerance test}

The mice were intraperitoneally injected with glucose $(1 \mathrm{~g} / \mathrm{kg}$ in $0.9 \% \mathrm{NaCl})$ after $14 \mathrm{~h}$ of fasting. Blood samples $(75-100 \mu \mathrm{l})$ were collected from the tail immediately before and 15, 30, 45 and $120 \mathrm{~min}$ after injection to determine glucose and insulin concentrations. Glucose concentrations were determined using a glucose strip on an Accu-Chek Performa II instrument (Roche).

\section{Intraperitoneal insulin tolerance test}

The non-fasting mice were intraperitoneally injected with insulin $(1 \mathrm{U} / \mathrm{kg})$. Blood glucose concentrations were measured using test strips (Accu-Chek Performa II; Roche) at baseline ( 0 min, before insulin administration) and 5, 10, 15, 20 and $30 \mathrm{~min}$ after insulin administration. Glucose measurements were then converted to the natural logarithm (Ln). The slope was calculated using linear regression (time $\times$ Ln(glucose)) and was multiplied by 100 to obtain the glucose

Table 2. Food intake and metabolic variables of mice fed the normalprotein diet (NP) or the low-protein diet (LP)

(Mean values with their standard errors, $n 6$ per group)

\begin{tabular}{|c|c|c|c|c|}
\hline & \multicolumn{2}{|c|}{ NP } & \multicolumn{2}{|c|}{ LP } \\
\hline & Mean & SE & Mean & SE \\
\hline Food intake (mg/g per d) & $97 \cdot 1$ & $5 \cdot 5$ & $118 \cdot 6^{*}$ & $8 \cdot 9$ \\
\hline Energy intake $(\mathrm{kJ} / \mathrm{d})$ & 59.58 & 3.64 & $60 \cdot 33$ & 3.09 \\
\hline Initial body weight $(\mathrm{g})$ & 13.4 & $1 \cdot 2$ & $12 \cdot 5$ & 0.6 \\
\hline Final body weight (g) & $28 \cdot 1$ & $2 \cdot 1$ & $20 \cdot 30^{*}$ & $1 \cdot 18$ \\
\hline Net weight gain $(\mathrm{g})$ & $14 \cdot 7$ & $2 \cdot 1$ & $7 \cdot 8^{\star}$ & $1 \cdot 1$ \\
\hline Fasting glucose (mmol/l) & 4.98 & 0.38 & $3.97^{*}$ & 0.42 \\
\hline Fasting insulin (pmol/l) & $3 \cdot 2$ & 0.28 & $2 \cdot 3^{\star}$ & 0.31 \\
\hline Non-fasting glucose (mmol/l) & $10 \cdot 42$ & 0.65 & $8 \cdot 7^{\star}$ & 0.57 \\
\hline Non-fasting insulin (pmol/l) & $53 \cdot 32$ & $3 \cdot 81$ & $31 \cdot 22^{*}$ & $5 \cdot 63$ \\
\hline
\end{tabular}

* Mean value was significantly different from that of the NP mice $(P<0.05)$. 

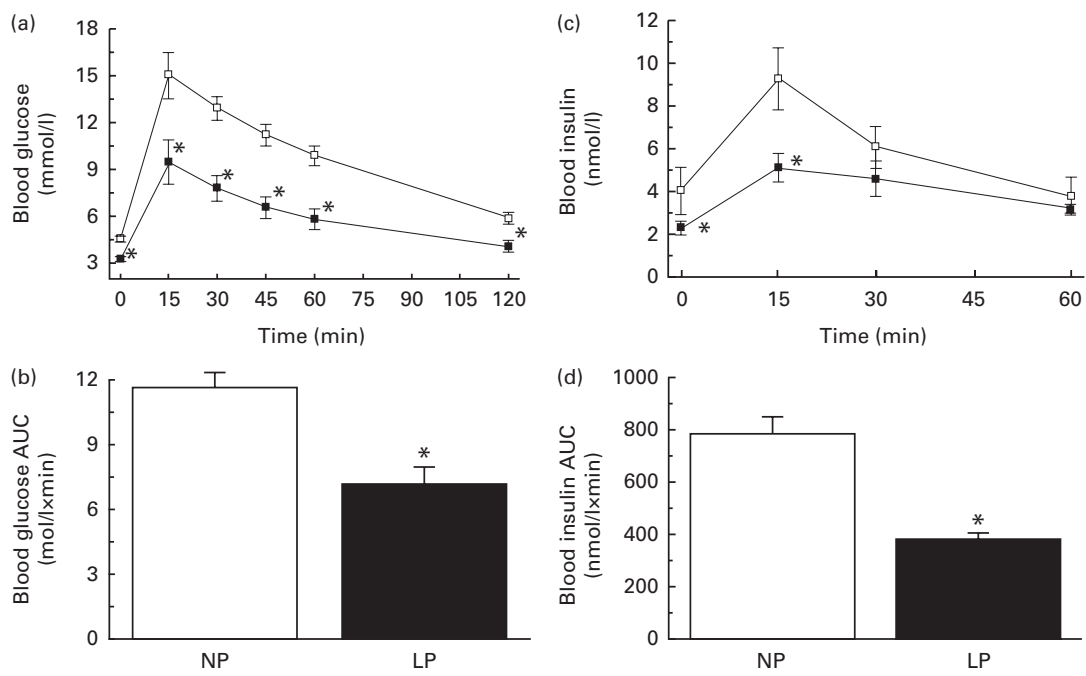

Fig. 1. (a) Glucose tolerance, (b) AUC of blood glucose during a glucose tolerance test (GTT), (c) blood insulin and (d) AUC of blood insulin during a GTT of $14 \mathrm{~h}$ fasting normal-protein diet (NP, - - -) and low-protein diet (LP, - - ) mice $0,15,30$ and $60 \mathrm{~min}$ after glucose administration. Values are means ( $n 6$ per group), with their standard errors represented by vertical bars. ${ }^{*}$ Mean value was significantly different from that of NP mice $(P<0.05)$.

decay constant rate during the insulin tolerance test $\left(k_{\mathrm{ITT}}\right)$ per $\min (\% / \mathrm{min})$. Insulin concentrations were measured using RIA, as described previously ${ }^{(30)}$.

\section{Evaluation of in vivo insulin clearance}

The plasma insulin concentrations of $\mathrm{C} 57 \mathrm{BL} / 6$ mice submitted to the intraperitoneal ITT were determined. Insulin clearance was evaluated as described previously ${ }^{(20)}$. The constant rate of insulin disappearance (insulin decay) was calculated by first converting insulin measurements to the $\mathrm{Ln}$; the slope was calculated using linear regression (time $\times \operatorname{Ln}($ insulin)) and was multiplied by 100 to obtain the insulin decay constant rate per $\min (\% / \mathrm{min})$. Insulin concentrations were measured using RIA, as described previously ${ }^{(30)}$.

\section{Statistical analyses}

Point-to-point comparisons were made using Student's $t$ test. The groups were also compared using Student's $t$ test. The results were considered significantly different if $P<0 \cdot 05$. Sample size was determined taking into account the size effect. Bilateral statistic with a significance level of $5 \%$ and potency of 0.98 was used to rule out type II errors. Under these conditions, the highest sample size required would be $n 5$ for the $k_{\text {ITT }}$ experiment; thus, we opted for a size of $n 6$ as a safety measure.

\section{Results}

\section{Food intake and metabolic variables}

Although the LP mice exhibited slightly increased food intake, these mice were isoenergetic at the end of the experiments compared with the NP mice. Additionally, the NP and LP mice had the same weight before the dietary intervention, but the LP mice had a lower weight compared with the NP mice after the 14-week dietary intervention. The lower weight gain was accompanied by lower plasma insulin concentrations and lower glycaemia under both fasting and non-fasting conditions, as shown in Table 2. To further understand how hyperglycaemia was prevented in the LP mice despite reduced insulinaemia, we first assessed the glucose tolerance of these mice.

\section{Glucose tolerance and insulin dynamics}

The LP mice were more glucose tolerant, as revealed by a glucose tolerance test (GTT) (Fig. 1(a)) and reflected by a lower AUC of glucose during the GTT (Fig. 1(b)). This phenomenon might occur mainly because of changes in the capacity of insulin to increase glucose uptake by the peripheral tissues (insulin sensitivity) and the plasma insulin concentrations during a GTT (insulin dynamics). The LP mice exhibited a remarkable change in insulin dynamics. First, there was a lower plasma insulin peak at $15 \mathrm{~min}$, followed by a slower reduction of insulin concentrations. At $30 \mathrm{~min}$, the insulin concentrations of the LP mice equalised those of the NP mice and remained comparable for at least $60 \mathrm{~min}$ after glucose administration (Fig. 1(c)). This equalisation was not enough to normalise the AUC of insulin during a GTT, which was lower in the LP mice (Fig. 1(d)).

\section{Insulin sensitivity}

The LP mice were more insulin sensitive, as revealed by the lower blood glucose values observed during an ITT (Fig. 2(a)) and increased $k_{\text {ITT }}$ (Fig. 2(b)). This condition resulted in a lower exposure of the peripheral tissues to glucose during the ITT, as revealed by the lower AUC of glucose (Fig. 2(c)). 

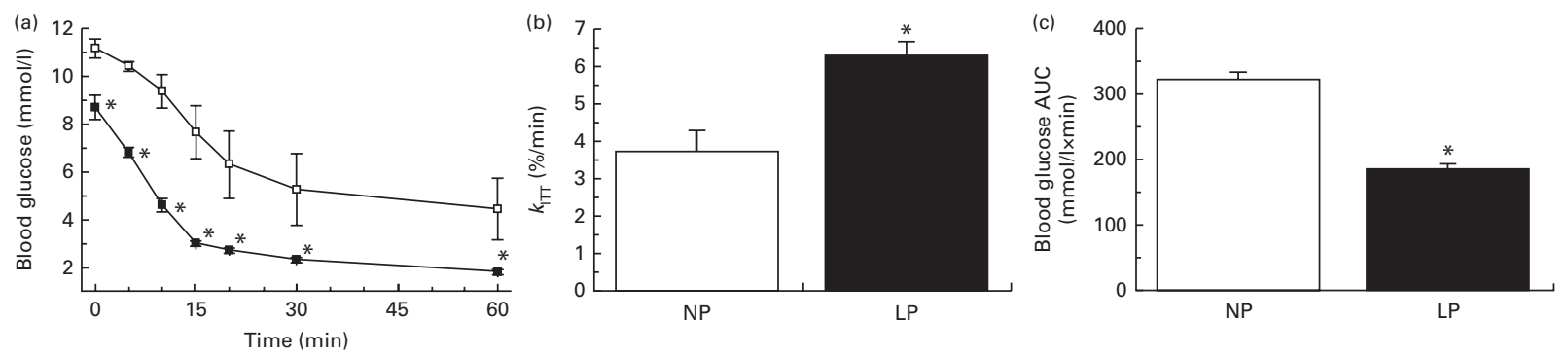

Fig. 2. (a) Insulin sensitivity, (b) glucose decay constant rate during the insulin tolerance test $\left(k_{1 T T}\right)$ and (c) AUC of blood glucose during an ITT of non-fasting normalprotein diet (NP, 다) and low-protein diet (LP, --$)$ mice. Values are means ( $n 6$ per group), with their standard errors represented by vertical bars. ${ }^{*}$ Mean value was significantly different from that of the NP mice $(P<0.05)$.

\section{Liver insulin signalling}

Higher insulin sensitivity was confirmed and could at least partially be explained by an increase in the phosphorylation of the insulin receptor (Fig. 3(a)), protein kinase B (AKT) (Fig. 3(b)), AMP-activated protein kinase (AMPK) (Fig. 3(c)) and acetyl-CoA carboxylase (Fig. 3(d)) in the liver of the LP mice.

\section{Insulin secretion and total insulin content}

The changes in insulin dynamics could be attributed to insulin produced by the pancreatic islets (insulin secretion) and/or insulin removed from the plasma (insulin clearance).
As expected, the pancreatic islets of the LP mice secreted less insulin under both sub-stimulatory $(2.8 \mathrm{mmol} / \mathrm{l})$ and supra-stimulatory ( $16.7 \mathrm{mmol} / \mathrm{l})$ glucose conditions (Fig. 4(a)). This reduction in insulin secreted by the pancreatic islets of the LP mice could be attributed to impaired islet function (lower glucose-stimulated insulin secretion) (Fig. 4(b)) and lower total pancreatic islet insulin content (Fig. 4(c)).

\section{Insulin clearance}

Reduced insulin secretion does not explain why the insulin concentrations of the LP mice were equal to those of the NP
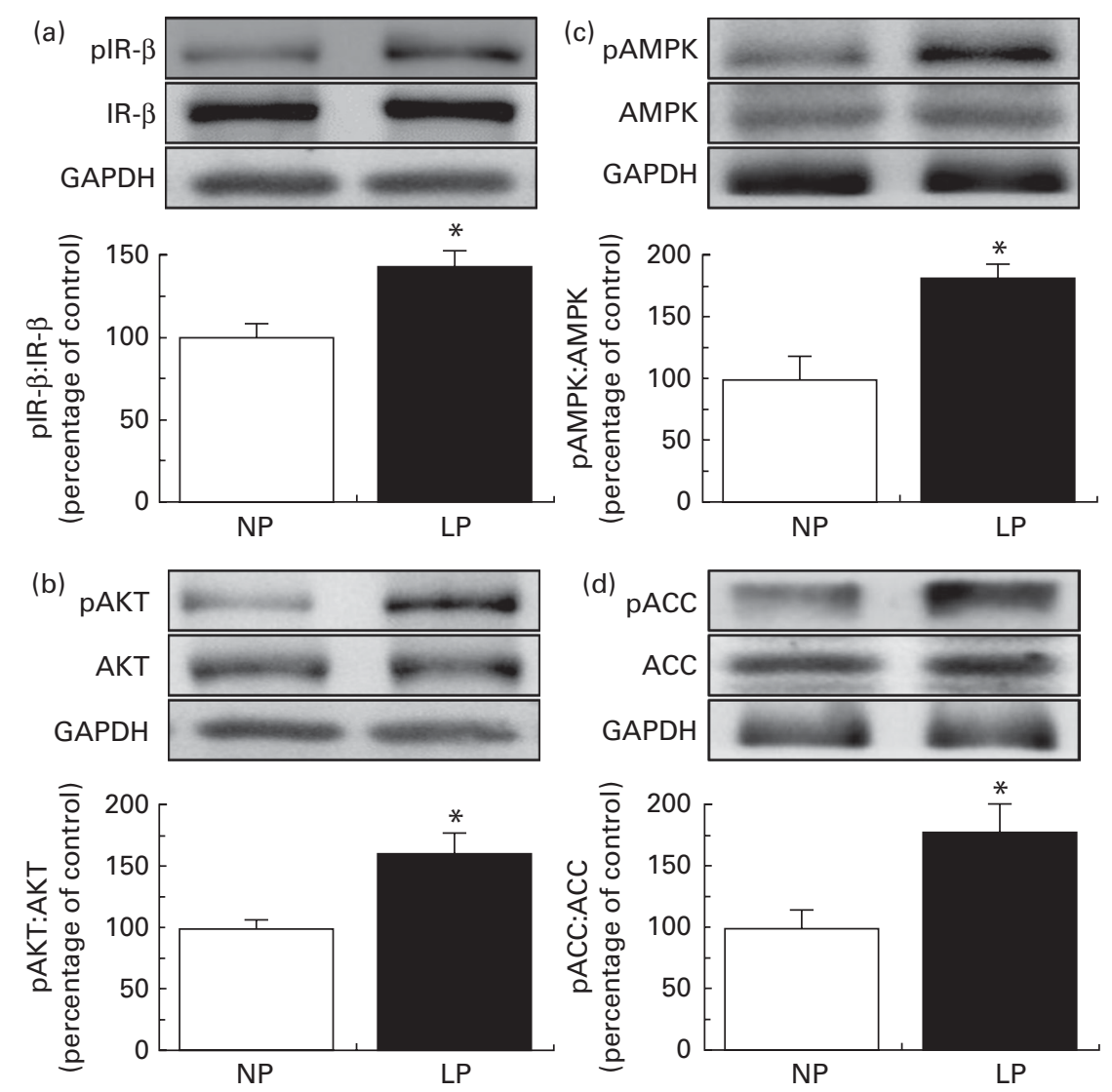

Fig. 3. Phosphorylation (p) of the (a) insulin receptor (IR), (b) protein kinase B (AKT), (c) AMP-activated protein kinase (AMPK) and (d) acetyl-CoA carboxylase $(A C C)$ in the liver of fasting normal-protein diet (NP) and low-protein diet (LP) mice. Data are expressed as a percentage of NP from the phosphorylated protein: total protein ratio. Values are means ( $n 6$ per group), with their standard errors represented by vertical bars. ${ }^{*}$ Mean value was significantly different from that of the NP mice $(P<0.05)$. GAPDH, glyceraldehyde 3-phosphate dehydrogenase. 


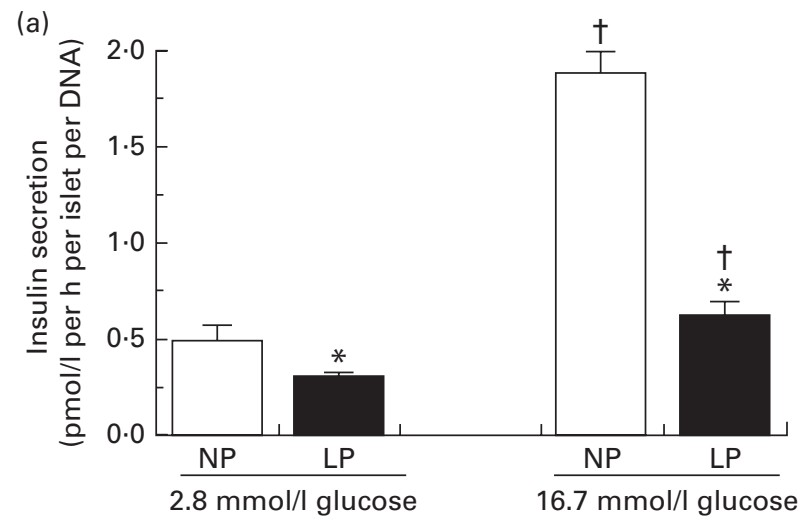

(b)
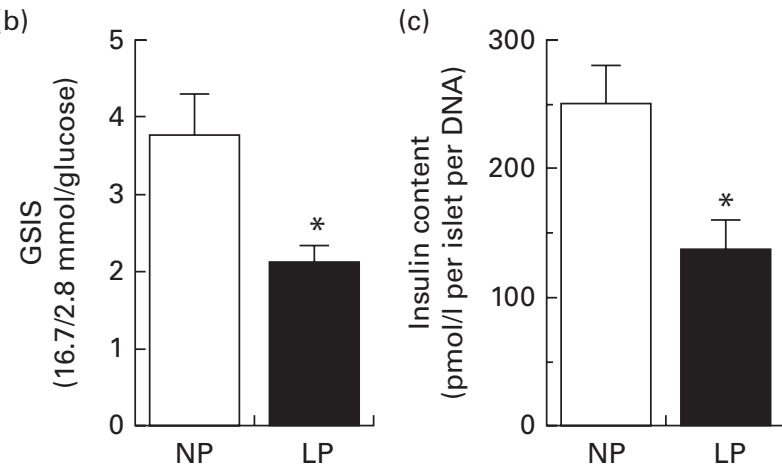

Fig. 4. (a) Insulin secretion, (b) glucose-stimulated insulin secretion (GSIS) and (c) total insulin content of pancreatic islets isolated from the normalprotein diet (NP) and low-protein diet (LP) mice. Values are means $(n 12$ per group), with their standard errors represented by vertical bars. * Mean value was significantly different from that of the NP mice $(P<0.05)$. †Mean value was significantly different from that of the respective $2.8 \mathrm{mmol} / \mathrm{l}$ glucose mice $(P<0.05)$.

mice from 30 to $60 \mathrm{~min}$ during the GTT. This apparent contradiction was resolved when we observed reduced insulin clearance (Fig. 5(a)) and slower insulin decay (Fig. 5(b)) in the LP mice. These events resulted in an increased availability of insulin after the administration of exogenous insulin (Fig. 5(c)).

\section{Insulin-degrading enzyme expression}

Given its major role in the control of insulin clearance and its possible effects on peripheral tissue insulin sensitivity, we also evaluated IDE expression in the liver, gastrocnemius muscle (GCK) and WAT. The expression of IDE was reduced by roughly $50 \%$ in the liver (Fig. 6(a)) and by about $25 \%$ in GCK (Fig. 6(b)), although it remained unchanged in the WAT (Fig. 6(c)).

\section{Discussion}

Most iterations of the thrifty phenotype share three major aspects: reduced insulin secretion by the pancreatic islets; increased insulin sensitivity in the peripheral organs; overall changes in organ development ${ }^{(4,5,15,17)}$

The present study provides solid evidence that mice fed a protein-restricted diet also exhibit reduced insulin clearance associated with reduced IDE expression mainly in the liver and, to a lesser extent, in the skeletal muscle also.

IDE is a $110 \mathrm{kDa}$ zinc metalloproteinase that is present in virtually every insulin-responsive tissue and that responds to the bulk of insulin that is removed and/or degraded from the plasma ${ }^{(24,27,31-37)}$. Many changes observed in the LP mice can at least partially be attributed to reduced IDE expression in the liver.

First, the primary function of IDE in insulin-responsive organs is to degrade and/or partially inactivate insulin, thus playing, as expected, a pivotal role in the promotion of insulin clearance $^{(24,27,31-37)}$. Therefore, it is not surprising that the reduced expression of IDE is often associated with reduced insulin clearance in many human and animal models ${ }^{(38-45)}$. The mounting evidence that alterations in IDE are closely related to the development of metabolic diseases, mainly type 2 diabetes, also supports the role of IDE in glucose
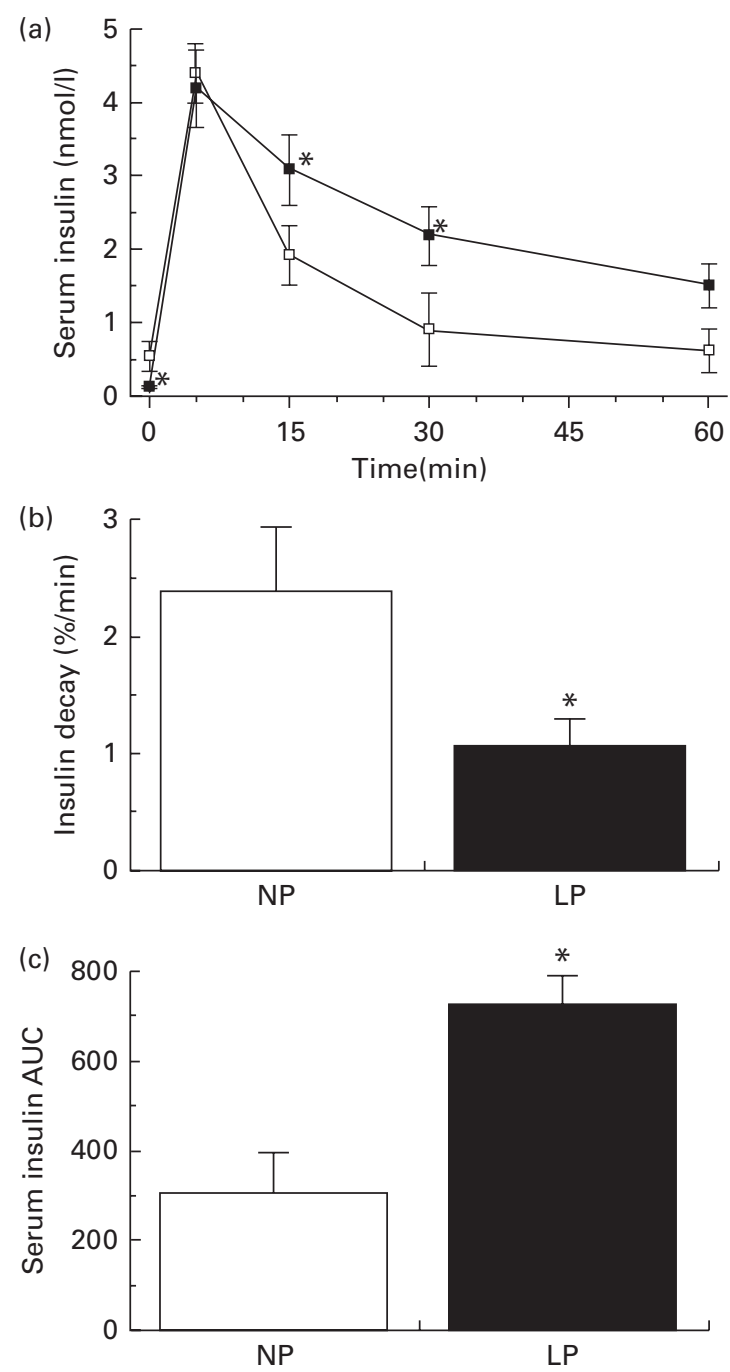

Fig. 5. (a) Insulin clearance, (b) insulin decay rate and (c) AUC of serum insulin during an insulin tolerance test of fasting normal-protein diet (NP) and low-protein diet (LP) mice. Values are means ( $n 6$ per group), with their standard errors represented by vertical bars. * Mean value was significantly different from that of the NP mice $(P<0.05)$. 

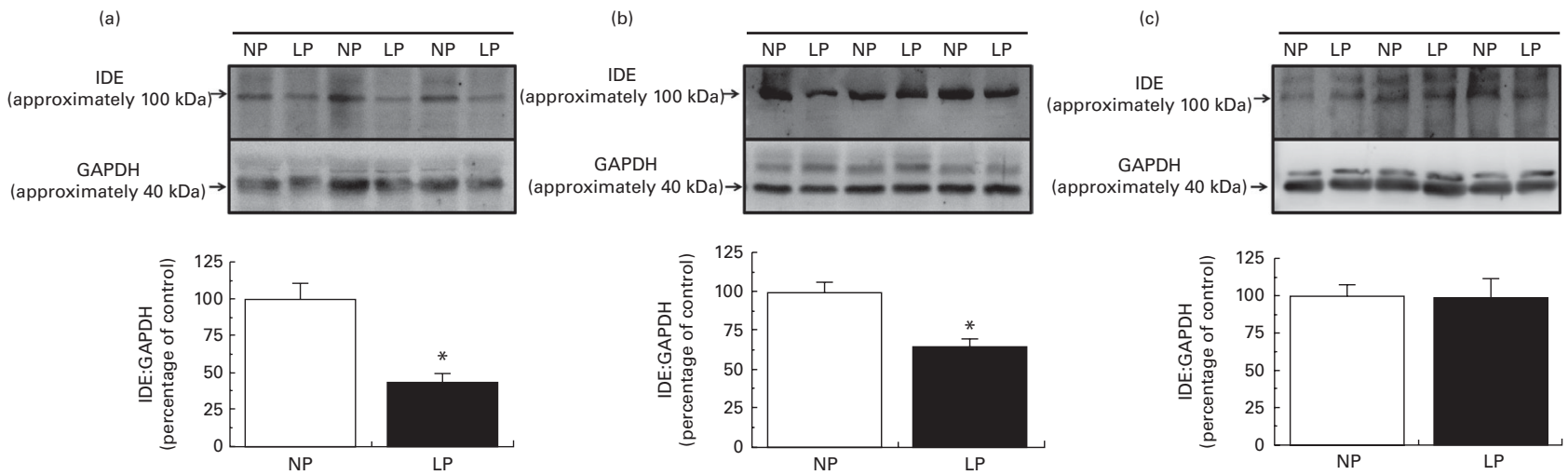

Fig. 6. Insulin-degrading enzyme (IDE) protein levels in the (a) liver, (b) gastrocnemius muscle and (c) white adipose tissue of fasting normal-protein diet (NP) and low-protein diet (LP) mice. Values are means ( $n 6$ per group), with their standard errors represented by vertical bars. ${ }^{*}$ Mean value was significantly different from that of the NP mice $(P<0 \cdot 05)$. GAPDH, glyceraldehyde 3-phosphate dehydrogenase.

homeostasis $^{(46-48)}$. It is likely that the reduction of IDE expression in the liver of the LP mice is the mechanism through which insulin clearance was reduced in our model. It has also recently been found that IDE expression in pancreatic islet $\beta$-cells is required for adequate insulin secretion $^{(49)}$, suggesting yet another role for this protein in the control of glucose homeostasis, which, although certainly relevant, was not the focus of the present study.

Second, once insulin binds to its receptor in insulinresponsive tissues, the receptor is internalised and continues to signal to downstream cascades, such as AKT, for as long as insulin is still bound to the receptor ${ }^{(31,50-52)}$. Therefore, the lower expression of IDE in LP mice may cause the insulin receptor to be active for a longer period, thus improving the effects of insulin and increasing the uptake of glucose. This hypothesis is also supported by evidence that the selective and specific inhibition of IDE in hepatocytes indeed leads to increased insulin receptor phosphorylation and possibly to increased glucose uptake $\mathrm{e}^{(31,35,50-57)}$.

Third, although insulin secretion was nearly four times lower in the LP mice, their plasma insulin concentrations under both fasting and non-fasting conditions were only approximately two times lower, which is apparently incongruous. However, once we consider that insulin clearance in the LP mice is half that in the NP mice, we find solid evidence that reduced IDE expression in the liver and subsequently lower insulin degradation contribute to the amelioration of plasma insulin concentrations in the LP mice, which could otherwise be even more hypoinsulinaemic.

The improvement of glucose tolerance and insulin sensitivity in the LP model used in the present study has recently been demonstrated by our research group ${ }^{(7)}$. The impairment of insulin secretion in response to glucose in LP rodents after weaning is related to the impairment of intracellular Ca handling ${ }^{(6)}$. Rats exposed to a protein-restricted diet have been found to exhibit lower glucose-induced insulin secretion and improved insulin signalling due to increased concentrations of the insulin receptor in the muscle ${ }^{(11)}$. From the results of the present study, it was found that insulin tolerance improved in the LP mice as a result of the lowering of the AUC values in the ITT and also elevation of the phosphorylated AMPK:AMPK and phosphorylated AKT:AKT ratios in the liver, despite no difference being observed in the phosphorylated AKT:AKT ratio in the liver of the insulin-stimulated animals, as described by Batista et al. ${ }^{(6)}$. However, there was no difference in the glycaemic and insulinaemic fasting levels, probably because the fasting time in the previous study ${ }^{(6)}$ was shorter than that in the present study. The reduced IDE levels found in the skeletal muscle constitute a corroborating evidence for this insulin-sensitising role of reduced IDE expression, even though it remained unchanged in the WAT. Nevertheless, considering the pivotal importance of liver IDE expression in insulin clearance, it is unlikely that this would have a meaningful impact on the reduced insulin clearance that we observed in the LP mice, which can more likely be attributed to the reduced IDE expression in the liver.

As has been suggested previously ${ }^{(17)}$, these changes are not a problem per se because when kept in a nutrient-restricted environment, animals and individuals do not develop type 2 diabetes. The actual problem occurs when animals and individuals are suddenly exposed to an excess-nutrient diet, such as a high-fat diet. Under this condition, these entities retain the thrifty phenotype while experiencing nutrient uptake significantly above their metabolic and physiological needs, leading to a process known as catch-up growth, in which animals gain increasingly more weight, particularly in the fat pads, quickly reaching and even surpassing the weight of NP mice ${ }^{(15,58-60)}$. This phenomenon leads to many detrimental changes in glucose homeostasis, mainly increased insulin resistance ${ }^{(60)}$ and impaired insulin secretion in response to several secretagogues, such as amino acids and neurotransmitters ${ }^{(10-12)}$. These events ultimately lead to an increased risk of metabolic disorders and type 2 diabetes $^{(4,17)}$.

In this context, we can speculate that the reduced insulin clearance that helps to manage hypoinsulinaemia in malnourished mice might lead to hyperinsulinaemia, which promotes responsive peripheral insulin resistance when the mice are exposed to a normal and/or a high-nutrient diet.

Although our animal model is not a thrifty phenotype per se, the evidence that we found in the present study might help to expand the knowledge about the thrifty phenotype, given that mice fed a protein-restricted diet not only produce and secrete 
less insulin, thus preserving nutrients and energy, but also remove and degrade less insulin, which could have the double benefit of sparing insulin while prolonging and potentiating its effects, possibly due to the down-regulation of IDE expression in the liver, and these changes could have implications for the actual instance of the thrifty phenotype.

\section{Acknowledgements}

The present study was funded by Fundação de Amparo à Pesquisa do Estado de São Paulo (FAPESP), National Counsel of Technological and Scientific Development (CNPq), and Obesity and Comorbidities Research Center (OCRC). FAPESP, CNPQ and OCRC had no role in the design and analysis of the study or in the writing of this article.

The authors' contributions are as follows: R. L. C. and L. F. R. designed the study; R. L. C., L. F. R., R. C. S. B. and A. P. G. C. conducted the study; R. L. C., L. F. R., E. M. C. and A. C. B. analysed the data; R. L. C. and L. F. R. wrote the article; E. M. C. and A. C. B. reviewed the article; L. F. R. had primary responsibility for the final content. All authors read and approved the final manuscript.

None of the authors has any conflicts of interest to declare.

\section{References}

1. DeFronzo RA (1992) Pathogenesis of type 2 (non-insulin dependent) diabetes mellitus: a balanced overview. Diabetologia 35, 389-397.

2. Remacle C, Dumortier O, Bol V, et al. (2007) Intrauterine programming of the endocrine pancreas. Diabetes Obes Metab 9, Suppl. 2, 196-209.

3. Snoeck A, Remacle C, Reusens B, et al. (1990) Effect of a low protein diet during pregnancy on the fetal rat endocrine pancreas. Biol Neonate 57, 107-118.

4. Hales CN \& Barker DJ (1992) Type 2 (non-insulin-dependent) diabetes mellitus: the thrifty phenotype hypothesis. Diabetologia 35, 595-601.

5. Hales CN (1997) Fetal and infant growth and impaired glucose tolerance in adulthood: the "thrifty phenotype" hypothesis revisited. Acta Paediatr Suppl 422, 73-77.

6. Batista TM, Ribeiro RA, da Silva PM, et al. (2013) Taurine supplementation improves liver glucose control in normal protein and malnourished mice fed a high-fat diet. Mol Nutr Food Res 57, 423-434.

7. Cappelli AP, Zoppi CC, Barbosa-Sampaio HC, et al. (2014) Taurine-induced insulin signalling improvement of obese malnourished mice is associated with redox balance and protein phosphatases activity modulation. Liver Int $\mathbf{3 4}$, $771-783$.

8. Camargo RL, Batista TM, Ribeiro RA, et al. (2013) Effects of taurine supplementation upon food intake and central insulin signaling in malnourished mice fed on a high-fat diet. Adv Exp Med Biol 776, 93-103.

9. Rafacho A, Giozzet VA, Boschero AC, et al. (2009) Reduced pancreatic beta-cell mass is associated with decreased FoxO1 and Erk1/2 protein phosphorylation in low-protein malnourished rats. Braz J Med Biol Res 42, 935-941.

10. Araujo EP, Amaral ME, Filiputti E, et al. (2004) Restoration of insulin secretion in pancreatic islets of protein-deficient rats by reduced expression of insulin receptor substrate (IRS)-1 and IRS-2. J Endocrinol 181, 25-38.
11. Latorraca MQ, Reis MA, Carneiro EM, et al. (1998) Protein deficiency and nutritional recovery modulate insulin secretion and the early steps of insulin action in rats. $J$ Nutr 128, 1643-1649.

12. Reis MA, Carneiro EM, Mello MA, et al. (1997) Glucose-induced insulin secretion is impaired and insulin-induced phosphorylation of the insulin receptor and insulin receptor substrate-1 are increased in protein-deficient rats. J Nutr 127, 403-410.

13. Masiello P (2006) Animal models of type 2 diabetes with reduced pancreatic beta-cell mass. Int J Biochem Cell Biol 38, 873-893.

14. Jolly MC, Hovorka R, Godsland I, et al. (2003) Relation between insulin kinetics and insulin sensitivity in pregnancy. Eur J Clin Invest 33, 698-703.

15. Hales CN (1997) Metabolic consequences of intrauterine growth retardation. Acta Paediatr Suppl 423, 184-187 (discussion 188).

16. Law CM (1996) Fetal and infant influences on non-insulindependent diabetes mellitus (NIDDM). Diabet Med 13, S49-S52.

17. Hales CN \& Barker DJ (2001) The thrifty phenotype hypothesis. Br Med Bull 60, 5-20.

18. Hwang DY, Seo S, Kim Y, et al. (2007) Significant change in insulin production, glucose tolerance and ER stress signaling in transgenic mice coexpressing insulin-siRNA and human IDE. Int J Mol Med 19, 65-73.

19. Park SY, Cho YR, Kim HJ, et al. (2006) Mechanism of glucose intolerance in mice with dominant negative mutation of CEACAM1. Am J Physiol Endocrinol Metab 291, E517-E524.

20. Ahrén B, Thomaseth K \& Pacini G (2005) Reduced insulin clearance contributes to the increased insulin levels after administration of glucagon-like peptide 1 in mice. Diabetologia 48, 2140-2146.

21. Meier JJ, Veldhuis JD \& Butler PC (2005) Pulsatile insulin secretion dictates systemic insulin delivery by regulating hepatic insulin extraction in humans. Diabetes 54, 1649-1656.

22. Valera Mora ME, Scarfone A, Calvani M, et al. (2003) Insulin clearance in obesity. J Am Coll Nutr 22, 487-493.

23. Mittelman SD, Van Citters GW, Kim SP, et al. (2000) Longitudinal compensation for fat-induced insulin resistance includes reduced insulin clearance and enhanced beta-cell response. Diabetes 49, 2116-2125.

24. Duckworth WC, Bennett RG \& Hamel FG (1998) Insulin degradation: progress and potential. Endocr Rev 19, 608-624.

25. Boden G, Ruiz J, Kim CJ, et al. (1996) Effects of prolonged glucose infusion on insulin secretion, clearance, and action in normal subjects. Am J Physiol 270, E251-E258.

26. Butterfield WJ (1970) Insulin clearance in nondiabetic and diabetic subjects. Panminerva Med 12, 233-235.

27. Authier F, Posner BI \& Bergeron JJ (1996) Insulin-degrading enzyme. Clin Invest Med 19, 149-160.

28. Santos GJ, Oliveira CA, Boschero AC, et al. (2011) CNTF protects MIN6 cells against apoptosis induced by Alloxan and IL-1 $\beta$ through downregulation of the AMPK pathway. Cell Signal 23, 1669-1676.

29. Rezende LF, Vieira AS, Negro A, et al. (2009) Ciliary neurotrophic factor (CNTF) signals through STAT3-SOCS3 pathway and protects rat pancreatic islets from cytokine-induced apoptosis. Cytokine 46, 65-71.

30. Rezende LF, Stoppiglia LF, Souza KL, et al. (2007) Ciliary neurotrophic factor promotes survival of neonatal rat islets via the BCL-2 anti-apoptotic pathway. J Endocrinol 195, 157-165.

31. Amata O, Marino T, Russo N, et al. (2009) Human insulindegrading enzyme working mechanism. I Am Chem Soc 131, 14804-14811. 
32. Fernández-Gamba A, Leal MC, Morelli L, et al. (2009) Insulin-degrading enzyme: structure-function relationship and its possible roles in health and disease. Curr Pharm Des 15, 3644-3655.

33. Hulse RE, Ralat LA \& Wei-Jen T (2009) Structure, function, and regulation of insulin-degrading enzyme. Vitam Horm 80, 635-648.

34. Kuo WL, Montag AG \& Rosner MR (1993) Insulin-degrading enzyme is differentially expressed and developmentally regulated in various rat tissues. Endocrinology 132, 604-611.

35. Duckworth WC, Hamel FG \& Peavy DE (1988) Hepatic metabolism of insulin. Am J Med 85, 71-76.

36. Duckworth WC (1988) Insulin degradation: mechanisms, products, and significance. Endocr Rev 9, 319-345.

37. Yonezawa K, Yokono K, Yaso S, et al. (1986) Degradation of insulin by insulin-degrading enzyme and biological characteristics of its fragments. Endocrinology 118, 1989-1996.

38. Rezende LF, Santos GJ, Santos-Silva JC, et al. (2012) Ciliary neurotrophic factor (CNTF) protects non-obese Swiss mice against type 2 diabetes by increasing beta cell mass and reducing insulin clearance. Diabetologia 55, 1495-1504.

39. Lu X, Huang Y, Liu Y, et al. (2009) Variants in the insulindegrading enzyme gene are associated with metabolic syndrome in Chinese elders. Metabolism 58, 1465-1469.

40. Rudovich N, Pivovarova O, Fisher E, et al. (2009) Polymorphisms within insulin-degrading enzyme (IDE) gene determine insulin metabolism and risk of type 2 diabetes. J Mol Med 87, 1145-1151.

41. Slominskil PA, Pivovarova OV, Shadrina MI, et al. (2009) Association of insulinase gene polymorphisms with type 2 diabetes mellitus in patients from the Moscow population. Genetika 45, 127-131.

42. Winkler C, Illig T, Koczwara K, et al. (2009) HHEX-IDE polymorphism is associated with low birth weight in offspring with a family history of type 1 diabetes. J Clin Endocrinol Metab 94, 4113-4115.

43. Furukawa Y, Shimada T, Furuta H, et al. (2008) Polymorphisms in the IDE-KIF11-HHEX gene locus are reproducibly associated with type 2 diabetes in a Japanese population. J Clin Endocrinol Metab 93, 310-314.

44. Kwak SH, Cho YM, Moon MK, et al. (2008) Association of polymorphisms in the insulin-degrading enzyme gene with type 2 diabetes in the Korean population. Diabetes Res Clin Pract 79, 284-290.

45. Groves CJ, Wiltshire S, Smedley D, et al. (2003) Association and haplotype analysis of the insulin-degrading enzyme (IDE) gene, a strong positional and biological candidate for type 2 diabetes susceptibility. Diabetes 52, 1300-1305.

46. Farris W, Mansourian S, Chang Y, et al. (2003) Insulindegrading enzyme regulates the levels of insulin, amyloid beta-protein, and the beta-amyloid precursor protein intracellular domain in vivo. Proc Natl Acad Sci U S A 100, 4162-4167.

47. Farris W, Mansourian S, Leissring MA, et al. (2004) Partial loss-of-function mutations in insulin-degrading enzyme that induce diabetes also impair degradation of amyloid beta-protein. Am J Pathol 164, 1425-1434.

48. Abdul-Hay SO, Kang D, McBride M, et al. (2011) Deletion of insulin-degrading enzyme elicits antipodal, age-dependent effects on glucose and insulin tolerance. PLOS ONE 6, e20818

49. Steneberg P, Bernardo L, Edfalk S, et al. (2013) The type 2 diabetes-associated gene ide is required for insulin secretion and suppression of $\alpha$-synuclein levels in $\beta$-cells. Diabetes $\mathbf{6 2}$, 2004-2014.

50. Leissring MA, Malito E, Hedouin S, et al. (2010) Designed inhibitors of insulin-degrading enzyme regulate the catabolism and activity of insulin. PLOS ONE 5, e10504.

51. Li CZ, Zhang SH, Shu CD, et al. (2002) Relationship between insulin-degrading enzyme activity and insulin sensitivity in cell model of insulin-resistance. Di Yi Jun Yi Da Xue Xue Bao 22, 151-154

52. Di Guglielmo GM, Drake PG, Baass PC, et al. (1998) Insulin receptor internalization and signalling. Mol Cell Biochem 182, 59-63.

53. Pivovarova O, Gögebakan O, Pfeiffer AF, et al. (2009) Glucose inhibits the insulin-induced activation of the insulindegrading enzyme in HepG2 cells. Diabetologia 52, 1656-1664.

54. Wiesenthal SR, Sandhu H, McCall RH, et al. (1999) Free fatty acids impair hepatic insulin extraction in vivo. Diabetes $\mathbf{4 8}$ 766-774

55. Seta KA \& Roth RA (1997) Overexpression of insulin degrading enzyme: cellular localization and effects on insulin signaling. Biochem Biophys Res Commun 231, 167-171.

56. Auletta M, Antoniello S \& Abrescia N (1994) Insulin-degrading activity in experimental liver cirrhosis of the rat. Enzyme Protein 48, 197-201

57. Sato H, Terasaki T, Mizuguchi H, et al. (1991) Receptorrecycling model of clearance and distribution of insulin in the perfused mouse liver. Diabetologia 34, 613-621.

58. Claris O, Beltrand J \& Levy-Marchal C (2010) Consequences of intrauterine growth and early neonatal catch-up growth. Semin Perinatol 34, 207-210.

59. Fagerberg B, Bondjers L \& Nilsson P (2004) Low birth weight in combination with catch-up growth predicts the occurrence of the metabolic syndrome in men at late middle age: the Atherosclerosis and Insulin Resistance study. I Intern Med 256, 254-259.

60. Cianfarani S, Germani D \& Branca F (1999) Low birthweight and adult insulin resistance: the "catch-up growth" hypothesis. Arch Dis Child Fetal Neonatal Ed 81, F71-F73. 